\title{
Crescimento e sobrevivência do catfish de canal (Ictalurus punctatus) e jundiá (Rhamdia sp) no outono-inverno do Rio Grande do Sul
}

\author{
Growth and survival of channel catfish (Ictalurus punctatus) and silver catfish \\ (Rhamdia sp) through autumn-winter in Rio Grande do Sul, Brazil
}

\author{
Luciano Sena de Souza $^{1}$ Juvêncio Luís Osório Fernandes Pouey ${ }^{2}$ \\ Sabrina Ortiz de Camargo ${ }^{3}$ Bernardo dos Santos Vaz
}

\section{RESUMO}

O catfish é um peixe de couro, com hábito alimentar onívoro, nativo dos Estados Unidos, tendo despertado interesse dos produtores e indústrias da região sul do Rio Grande do Sul, devido à qualidade da carne, crescimento e facilidade de manejo. o jundiá também é um peixe de couro com hábito alimentar onívoro, apresentando bom desenvolvimento e fácil reprodução, sendo necessário avaliar seu potencial em sistemas de produção intensiva. $O$ objetivo deste trabalho foi comparar o desempenho e sobrevivência do catfish, jundiá cinza e albino. O experimento foi realizado na estação de piscicultura do Chasqueiro, localizada no município de Arroio Grande - RS, no período de abril a agosto de 2001, tendo a duração de 135 dias. Utilizaram-se 120 juvenis de catfish $(91,8 \pm 25,8 \mathrm{~g}), 120$ de jundiá albino $(83,7 \pm 20,9 \mathrm{~g})$ e 120 de jundiá cinza $(80,4 \pm 12,5 \mathrm{~g})$, distribuídos em 3 tanques de terra retangulares, com $180 \mathrm{~m}^{2}$, divididos longitudinalmente em três parcelas, formando um total de 9 divisões de $60 \mathrm{~m}^{2}$ cada. Os peixes foram colocados em uma densidade de 0,6 peixe $/ \mathrm{m}^{2}$ da área, $e$ alimentados com ração comercial extrusada (PB 36\%) na ordem de $3 \%$ da biomassa ao dia. Durante o período experimental avaliou-se o ganho de peso, o crescimento e a sobrevivência dos animais. A temperatura da água variou entre 11 e $29^{\circ} \mathrm{C}$, com média de $18,5^{\circ} \mathrm{C}$. Os resultados indicaram um ganho de peso no período de 40,4; 74,1 e 109,1g e sobrevivencias de 14, 32 e 63\% para o catfish, jundiá albino e cinza, respectivamente. Concluise que o jundiá cinza apresentou o melhor desempenho produtivo no período analisado.

Palavras-chave: Ictalurus punctatus, Rhamdia sp, crescimento, ganho-de-peso, tanque de terra, temperatura.

\begin{abstract}
Channel catfish is a skin fish, omnivorous, native of the United States of America, and it has interested fish farmers and industries of Southern Rio Grande do Sul, Brazil due to its meat quality, growth and management characteristics. Silver catfish is also a skin fish, omnivorous, showing good growth and reproduction, but lacking additional evaluation of its intensive cultivation. The objective of this work was to compare the performance and survival of channel catfish, gray and albine strains of silver catfish. The experiment was carried out at the Chasqueiro aquaculture facilities, in Arroio Grande county - RS - Brazil, through 135 days, from April to August of 2001. One Hundred and twenty channel catfish juveniles $(91.8 \pm 25.8 \mathrm{~g}), 120$ albine silver catfish juveniles $(83.7 \pm 20.9 \mathrm{~g})$ and 120 gray silver catfish juveniles $(80.4 \pm 12.5 \mathrm{~g})$ were distributed in three rectangular earth tanks, measuring $180 \mathrm{~m}^{2}$, alocated longitudinally in three plots, with a total of 9 divisions of $60 \mathrm{~m}^{2}$ each, with a stocking density of $0, .6$ fish $\mathrm{m}^{-2}$, fed daily with an extruded commercial food (CP 36\%), on a $3 \%$ biomass basis. Growth, weight gain and survival of the animals were evaluated. The water temperature ranged from 11 to $29^{\circ} \mathrm{C}$, with an average of $18.5^{\circ} \mathrm{C}$. Results indicated a weight gain of 40.4; 74.1 and $109.1 \mathrm{~g}$ and survivals of 14, 32 and 63\%, respectively for channel catfish, albine silver catfish and gray silver catfish. It can be concluded that gray silver catfish showed the best productive performance.
\end{abstract}

Key words: Ictalurus punctatus, Rhamdia sp, growth, weight gain, earth tank, temperature.

${ }^{1}$ Universidade Federal de Pelotas (UFPel), Brasil.

${ }^{2}$ Departamento de Zootecnia da Faculdade de Agronomia Eliseu Maciel, UFPel, CP 354, 96001-970, Pelotas, RS, Brasil. E-mail: juvencio@ufpel.tche.br. Autor para correspondência.

${ }^{3}$ Universidade Federal de Pelotas (UFPel), Brasil

${ }^{4}$ Universidade Federal de Pelotas (UFPel), Brasil. 


\section{INTRODUÇÃO}

O catfish é um representante da ordem Siluriformes, família Ictaluridae, caracterizando-se por não possuir escamas, apresentar barbilhões sensitivos e ser onívoro (LEE, 1991). É uma espécie originária dos estados do Golfo do México e do Vale do Mississipi nos Estados Unidos. Encontra-se introduzido em províncias do Canadá e em todo os Estados Unidos, assim como em muitos outros países do mundo (WELLBORN, 1988). Segundo LEWIS (1985), seriam necessários, pelo menos, 250 dias do ano com temperatura superior a $15,5^{\circ} \mathrm{C}$ para ser viabilizado o cultivo econômico deste peixe. LOVELL (1989) afirma que o catfish pode atingir $500 \mathrm{~g}$ de peso vivo em seis meses de cultivo, partindo de juvenis com $10 \mathrm{~g}$, desde que a temperatura da água esteja sempre acima de $23^{\circ} \mathrm{C}$.

O jundiá pertence à ordem Siluriformes, família Pimelodidae, gênero Rhamdia. A sistemática do gênero é confusa desde que foi descrita. Recentemente, SILFVERGRIP (1996) realizou uma ampla revisão taxonômica, baseada em caracteres da morfologia interna e externa, e concluiu que o gênero Rhamdia é formado por apenas 11 espécies dentro das 100 anteriormente descritas. Morfologicamente, o jundiá caracterizase por possuir boca sem dentes e corpo sem escamas, possuindo barbilhões de forma cilíndrica com comprimento variando proporcionalmente ao tamanho do espécime (GUEDES, 1980). Atualmente as técnicas de reprodução do jundiá estão dominadas, faltando as determinações relacionadas à nutrição, sistemas de cultivo e melhoramento genético da espécie.

O jundiá cinza é habitante natural da maioria dos lagos, rios, lagoas e mananciais de água doce do Rio Grande do Sul. Com o avanço da reprodução artificial foi realizada uma seleção genética de indivíduos homozigotos recessivos albinos. Estes representantes, salvo o par de alelos responsáveis pela coloração, são geneticamente idênticos a espécie que pertencem, não sendo facilmente encontrados na natureza, certamente devido ao alto grau de predação que sofrem (VARGAS \& MOREIRA, 1998).

Este trabalho foi realizado com o objetivo de avaliar o desempenho (crescimento, ganho de peso, taxa de crescimento específico, conversão alimentar e ganho de biomassa) e a sobrevivência do catfish e do jundiá cinza e albino em um sistema intensivo de cultivo durante as estações de outono - inverno no Rio Grande do Sul.

\section{MATERIAL E MÉTODOS}

O presente estudo foi realizado na estação de piscicultura do Chasqueiro, localizado no município de Arroio Grande, Rio Grande do Sul, pertencente à Universidade Federal de Pelotas. O experimento foi realizado durante 135 dias, com início em abril e término em agosto, abrangendo as estações de outono e inverno do ano de 2001. Os juvenis de jundiá e de catfish foram adquiridos nas estações de piscicultura do Chasqueiro e da Barragem Santa Bárbara, esta última pertencente à Universidade Católica de Pelotas.

Durante o período experimental, foram preparados três tanques retangulares de terra de $180 \mathrm{~m}^{2}$, divididos longitudinalmente com telas plásticas em três parcelas de $60 \mathrm{~m}^{2}$, correspondendo a três repetições. Dentro de cada parcela, os peixes permaneceram em uma densidade de 0,6 peixe a cada $1 \mathrm{~m}^{2}$. A densidade foi escolhida de acordo com a densidade que os produtores da região mais utilizam. Os viveiros possuíam em média $1,0 \mathrm{~m}$ de profundidade e sistema de entrada e saída d'água separado em cada subdivisão. Os viveiros foram preparados com uma calagem, cujo objetivo foi proporcionar uma melhor qualidade de água, principalmente em relação às características de $\mathrm{pH}$, dureza e alcalinidade.

Antes de serem transferidos aos viveiros, os animais foram avaliados biometricamente, através de balança digital e ictiômetro, determinando-se o peso corporal $(\mathrm{g})$, comprimento padrão (da sínfise mandibular até o início da nadadeira caudal) e total (da sínfise mandibular até extremo médio da nadadeira caudal). Os peixes foram distribuídos em cada subdivisão, alternando-se apenas a localização de cada tratamento de um viveiro para outro. Os três lotes foram classificados, como segue: tratamento 1 correspondente a 120 juvenis de catfish $(91,8 \pm 25,82 \mathrm{~g})$, tratamento 2 a 120 juvenis de jundiá albino $(83,7 \pm 20,98 \mathrm{~g})$ e o tratamento 3 a 120 juvenis de jundiá cinza $(80,4 \pm 12,52 \mathrm{~g})$.

Os peixes foram pesados e medidos no início e no fim do experimento. Durante o estudo, foram realizadas amostragens quinzenais de $12 \%$ dos animais. A captura dos peixes foi realizada através do arrasto de rede dentro de cada parcela, observando-se a presença de parasitos e possíveis lesões provenientes de predação. Frente aos valores obtidos nas diversas biometrias, foi calculado o ganho de peso $(\mathrm{g})$ : através da diferença do peso final e inicial; ganho de biomassa $\left(\mathrm{g} \mathrm{m}^{-2}\right)$ : resultado da diferença da biomassa final pela inicial, dividida pela

Ciência Rural, v.35, n.4, jul-ago, 2005. 
área; conversão alimentar aparente: obtida mediante ao cálculo da quantidade de ração fornecida dividida pelo ganho de peso; taxa de crescimento específico $\left(\mathrm{G}=(\ln\right.$ peso $2-\ln$ peso 1$) \times 100 \mathrm{t}^{-1}$, onde $\ln$ : logarítimo neperiano, peso 2: peso final da amostra, peso 1: peso inicial da amostra e t: tempo em dias) e sobrevivência $(\%)$, através da divisão dos sobreviventes pela população inicial x 100 .

Durante a execução do experimento, a água dos tanques era analisada a cada 15 dias, determinando-se: oxigênio dissolvido, $\mathrm{pH}$ e condutividade, através de oxímetro (YSI-55), phmetro (F-1002, Bernauer Aquicultura) e condutivímetro (F1000, Bernauer Aquicultura). A temperatura da água foi aferida diariamente, através de termômetro. Os peixes receberam como alimentação ração supra catfish ${ }^{\circledR}(36 \%)$ duas vezes ao dia numa taxa de $3 \%$ da biomassa.

O delineamento experimental utilizado foi completamente casualizado, com três tratamentos e três repetições. Os dados coletados foram analisados com o programa Statistica 6.0, através de análise de variância (ANOVA), regressão linear e comparação das médias pelo teste de Tukey, considerando-se as diferenças significativas ao nível de probabilidade de $\mathrm{P} \leq 0,05$.

\section{RESULTADOS E DISCUSSÃO}

As análises das características físicas e químicas da água não mostraram diferença significativa entre os tanques. Durante o período, o $\mathrm{pH}$ variou entre 6,5 e 7,7, o oxigênio dissolvido, entre 5,8 e $8,1 \mathrm{mg} \mathrm{L}^{-1}$, a condutividade oscilou de 78 a $108 \mu \mathrm{S}$ $\mathrm{cm}^{-1} \mathrm{e}$ a temperatura da água entre 11 e $29^{\circ} \mathrm{C}$, média de $18,5^{\circ} \mathrm{C}$.

Em comparação às variações ocorridas no período experimental, o catfish foi cultivado dentro dos parâmetros adequados para a espécie, mas a temperatura foi inferior a preconizada por LEWIS (1985) para o melhor desempenho da espécie, que está em torno de $29^{\circ} \mathrm{C}$. Em relação à concentração de oxigênio dissolvido, níveis próximos a $4 \mathrm{ppm}$, diminuem o crescimento do catfish, podendo ocasionar o aparecimento de doenças, devido ao estresse (MASSER et al., 1989). Com relação ao $\mathrm{pH}$, essa espécie suporta variações entre 4,0 a 9,0, sendo o ideal em torno de 7,4 (PIEDRAS, 1990).

O jundiá, sendo uma espécie nativa, apresenta boa rusticidade, principalmente a grandes oscilações de temperatura e baixos níveis de oxigênio dissolvido na água (GOMES et al., 2000). Segundo
LOPES et al. (2001), as larvas desta espécie apresentam melhor crescimento e sobrevivência em um $\mathrm{pH}$ em torno de 8,0 a 8,5 , entretanto para alevinos a melhor faixa situa-se entre 5,0 e 9,0, na qual ocorre uma pequena diminuição dos níveis corporais de $\mathrm{Na}^{+}$(ZAIONS \& BALDISSEROTTO, 2000). CHIPPARI-GOMES et al. (1999), estudando o efeito de temperaturas letais, concluíram que alevinos aclimatados em $21^{\circ} \mathrm{C}$ suportam temperaturas de $15,01^{\circ} \mathrm{C}$ a $29,25^{\circ} \mathrm{C}$. LUCHINI (1992) relata que o jundiá pode apresentar doenças, estresse, diminuição do crescimento e morte se o teor de oxigênio estiver igual ou abaixo de $4 \mathrm{mg} \mathrm{L}^{-1}$ por longos períodos. Comparando estes relatos com as variações de temperatura, $\mathrm{pH}$ e oxigênio dissolvido, no decorrer deste estudo, pode-se considerar que estes aspectos não devem ter influenciado negativamente no desempenho desta espécie.

A análise de comprimento médio final dos peixes não apresentou diferença significativa $(\mathrm{P} \leq 0,05)$ entre os tratamentos. O comprimento total médio inicial de $22,1 \mathrm{~cm}$ e peso médio de $91,8 \mathrm{~g}$, encontrado no catfish, mostram-se semelhantes aos dados relatados por PIEDRAS et al. (1991), que descrevem um comprimento total de $19 \mathrm{~cm}$ para peixes na faixa de peso de $56,6 \mathrm{~g}$.

CARDOZO (2000), em estudo da biometria, composição corporal e composição da carcaça do jundiá (Rhamdia sp), encontrou 59,2\% de rendimento de carcaça em peixes de comprimento médio total de $30,3 \mathrm{~cm}$ e faixa de peso entre $250 \mathrm{e}$ $350 \mathrm{~g}$. Este relato, mesmo em peixes com maior peso, demonstra coerência, quando comparado ao comprimento total de $26,1 \mathrm{~cm}$ e peso de $189,5 \mathrm{~g}$, encontrado para o jundiá cinza no final do período experimental.

De acordo com as biometrias quinzenais, foi possível observar o aumento do comprimento total $(\mathrm{cm})$ dos peixes durante o período de cultivo (Figura 1). Em relação ao peso médio final, o jundiá albino $(157,8 \mathrm{~g})$ foi significativamente mais pesado que o catfish $(132,2 \mathrm{~g})$ e menos pesado em relação ao jundiá cinza $(189,5 \mathrm{~g})$, constatando-se que o jundiá por ser uma espécie autóctone, é menos sensível às variações de temperatura no outono inverno da região sul do Rio Grande do Sul. Outro aspecto que deve ser observado é que o jundiá, nesta faixa de peso, pode apresentar um maior potencial de crescimento. A regressão linear do ganho de peso em relação aos 135 dias de cultivo, não demonstra uma grande diferença entre o jundiá albino e o jundiá cinza; já o catfish revela uma linha 


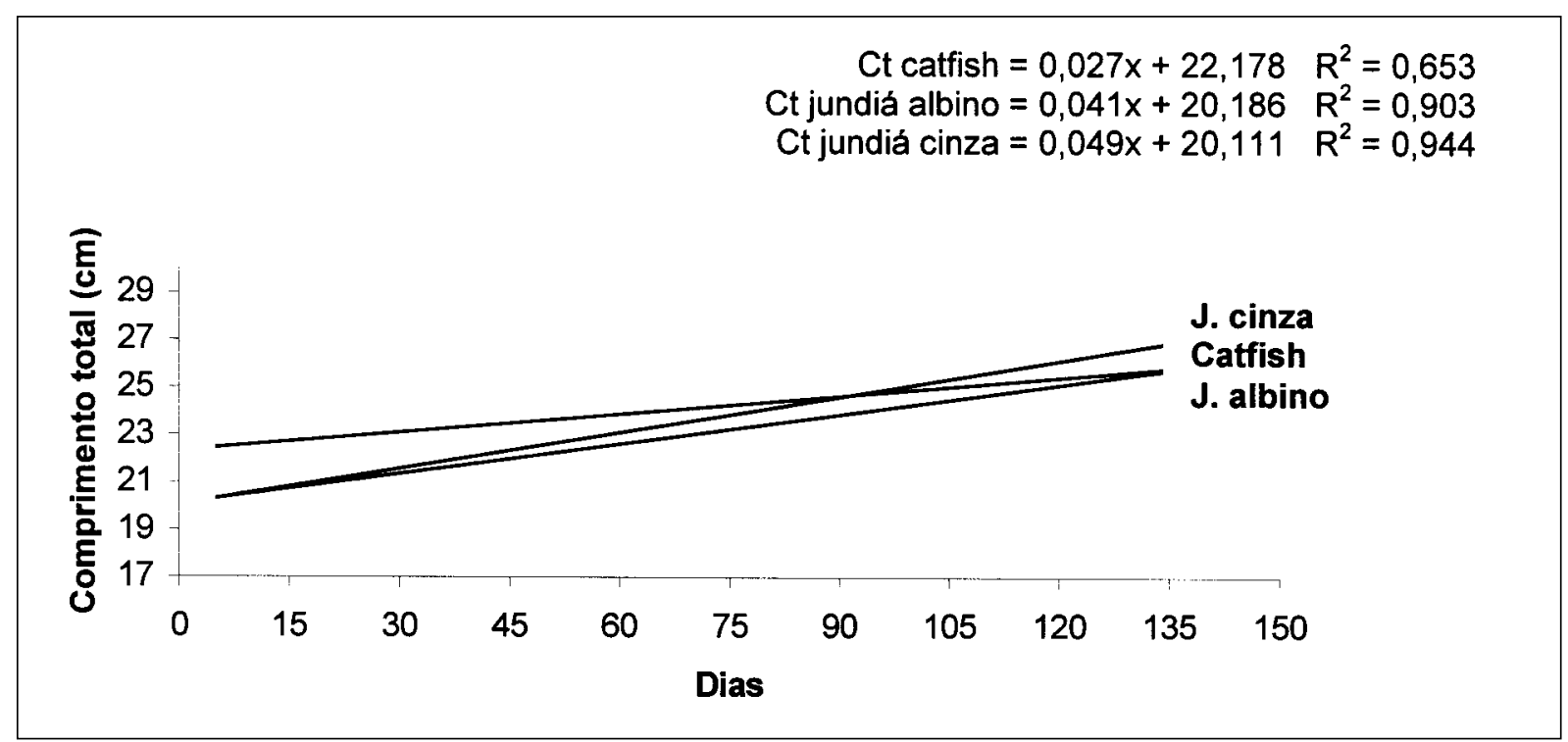

Figura 1 - Evolução do comprimento total do catfish americano, jundiá albino e jundiá cinza, criados por 135 dias durante o período de outono-inverno do Rio Grande do Sul.

de tendência diferenciada em relação aos jundiás, devido ao menor crescimento e ao baixo coeficiente de correlação encontrados (Figura 2).

O jundiá cinza e o jundiá albino apresentaram um ganho de peso e ganho de biomassa significativamente superior ao catfish $(\mathrm{P}<0,05)$. Entre os representantes da espécie Rhamdia sp, o jundiá cinza foi significativamente superior $(\mathrm{P}<0,05)$. Em relação à taxa de crescimento específico não foram obtidas diferenças significativas entre o jundiá albino e cinza, mas foram superiores ao catfish (Tabela 1). Durante o arraçoamento dos animais, observou-se que nos dias de menor temperatura $\left(11^{\circ} \mathrm{C}\right)$, o catfish não era visualizado na superfície da lâmina d’água alimentando-se, fato este que poderia justificar os menores índices produtivos no período.

O Rhamdia quelen pode ser considerado uma espécie euritérmica, pois alevinos aclimatados a $31^{\circ} \mathrm{C}$ suportam temperaturas de 15 a $34^{\circ} \mathrm{C}$. A aclimatação

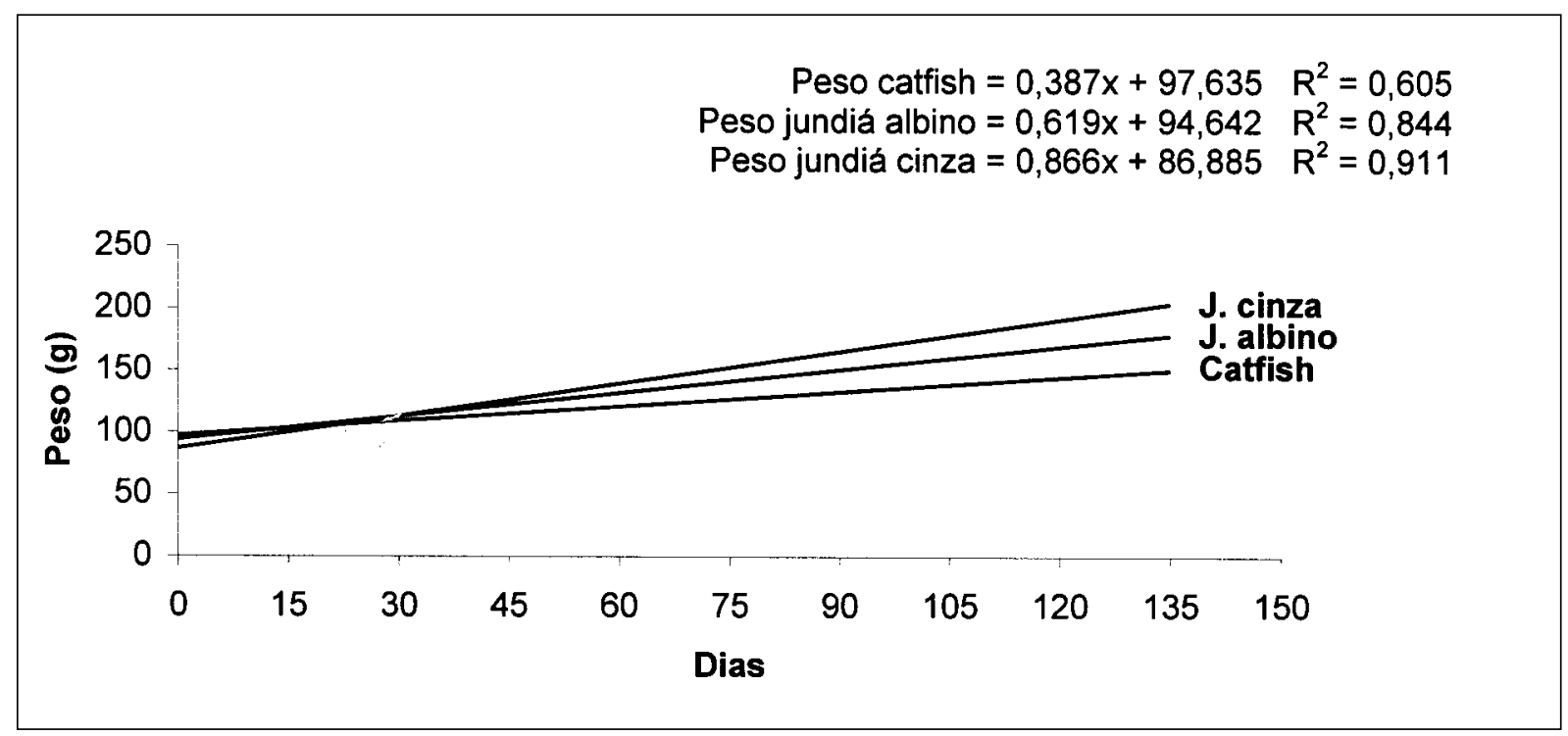

Figura 2 - Evolução do peso do catfish americano, jundiá albino e jundiá cinza, criados por 135 dias durante o período de outono-inverno do Rio Grande do Sul.

Ciência Rural, v.35, n.4, jul-ago, 2005. 
a temperaturas mais baixas proporciona uma maior tolerância à redução de temperatura, mas o limite superior de tolerância não se altera (CHIPPARIGOMES et al., 1999). Este relato corrobora a menor sensibilidade dos jundiás cinza e albino com as menores temperaturas observadas durante este estudo, já que é uma espécie adaptada ao clima da região.

GOMES \& SCHLINDWEIN (2000), estudando o ganho de peso de juvenis de catfish, possuindo $80 \mathrm{~g}$ de peso inicial, cultivados com ração de $32 \%$ de proteína bruta em uma densidade de 0,75 peixe $\mathrm{m}^{-2}$, obtiveram como resultado um ganho de peso médio individual de $182,3 \mathrm{~g}$ e conversão alimentar de 1,3:1, os peixes foram criados numa temperatura média de $24,1^{\circ} \mathrm{C}$, durante 150 dias. Em pesquisa realizada com a mesma espécie (peso inicial de 57,6g), durante 158 dias, na densidade de $0,6 \mathrm{~m}^{-2} \mathrm{e}$ temperatura média de $22,3^{\circ} \mathrm{C}$, foi alcançado ganho de peso médio de 448,5g e conversão alimentar de 2,4:1 (PIEDRAS et al., 1991). KIM \& LOVELL (1995), num estudo do efeito da restrição alimentar nesta espécie (41g), obtiveram nos peixes, sem restrição, um ganho de peso de $509 \mathrm{~g}$ em 126 dias, numa temperatura média de $25^{\circ} \mathrm{C}$ e densidade de 0,7 peixe $\mathrm{m}^{-2}$.

Segundo STEFFENS (1987), a influência térmica sobre a taxa metabólica dos peixes varia muito de uma espécie para outra. $\mathrm{O}$ catfish requer uma temperatura em torno de $30^{\circ} \mathrm{C}$ para demonstrar todo o seu potencial de desenvolvimento (ANDREWS et al., 1972; ANDREWS \& STICKNEY, 1972). Portanto, com as oscilações de temperatura ocorridas neste experimento, fica justificável o menor ganho de peso $(40,4 \mathrm{~g})$ e pior conversão alimentar alcançado pelo catfish, numa temperatura média de $18,5^{\circ} \mathrm{C}$.

Ao analisarmos os índices de sobrevivência, observamos que o jundiá cinza foi significativamente superior ao jundiá albino e ao catfish (Tabela 1). Observa-se que a maior sobrevivência do jundiá cinza pode estar relacionada a esta espécie ser nativa e possuir uma camuflagem mais eficaz frente à predação. Mesmo sem haver uma quantificação precisa, pode-se observar que as lesões provenientes de predação apareceram em torno de duas vezes mais no catfish e três vezes mais no jundiá albino, quando comparados ao jundiá cinza. SATO \& AMARAL JUNIOR (2003) também encontraram uma maior sobrevivência do jundiá cinza $(56,9 \%)$ frente ao albino $(33,3 \%)$, em um experimento durante 240 dias de cultivo, na forma de consórcio, que incluiu também a tilápia.

CHO \& LOVELL (2002) após 133 dias de cultivo do catfish $(245,7 \mathrm{~g})$ numa densidade de 0,7 peixe $\mathrm{m}^{-2}$ e temperatura de $29^{\circ} \mathrm{C}$, observaram uma taxa de sobrevivência de $94 \%$. Num estudo sobre efeitos do período de cultivo e densidade de estocagem sobre o desempenho do catfish (211g), durante 150 dias é descrita uma taxa de sobrevivência de $92 \%(0,7$ peixe $\mathrm{m}^{-2}$ ), numa temperatura média de $24,1^{\circ} \mathrm{C}$ (GOMES \& SCHLINDWEIN, 2000). Frente a estes relatos e com as oscilações térmicas ocorridas, o catfish pode ter sofrido um estresse térmico muito grande, fato que unido à predação, pode ter favorecido o menor índice de sobrevivência encontrado.

\section{CONCLUSÕES}

O jundiá cinza é menos sensível às oscilações térmicas do outono-inverno do extremo sul do Rio Grande do Sul, apresentando um melhor ganho de peso, ganho de biomassa e taxa de sobrevivência que o jundiá albino e o catfish. O jundiá cinza apresentou melhor conversão alimentar, sendo 1,4 vez mais eficiente que o jundiá albino e 2,6 vezes mais que o catfish. O jundiá albino apresentou melhor ganho de peso, conversão alimentar, ganho de biomassa e sobrevivência que o catfish.

Tabela 1 - Parâmetros do catfish americano, jundiá albino e jundiá cinza, criados por 135 dias durante o período de outono-inverno do Rio Grande do Sul.

\begin{tabular}{lccc}
\hline Parâmetro/Tratamento & Catfish & Jundiá albino & Jundiá cinza \\
\hline Janho de peso $(\mathrm{g})$ & $40,4 \pm 20,19^{\mathrm{c}}$ & $74,1 \pm 24,87^{\mathrm{b}}$ & $109,1 \pm 35,33^{\mathrm{a}}$ \\
$\mathrm{J}^{*}(\%)$ & $0,27 \pm 0,11^{\mathrm{b}}$ & $0,46 \pm 0,18^{\mathrm{a}}$ & $0,63 \pm 0,21^{\mathrm{a}}$ \\
Janho de biomassa $\left(\mathrm{g} / \mathrm{m}^{2}\right)$ & $26,9 \pm 13,46^{\mathrm{c}}$ & $49,4 \pm 16,58^{\mathrm{b}}$ & $72,7 \pm 23,55^{\mathrm{a}}$ \\
Sonversão alimentar aparente & $8,3 \pm 2,73^{\mathrm{a}}$ & $4,5 \pm 2,13^{\mathrm{b}}$ & $3,09 \pm 1,87^{\mathrm{b}}$ \\
Sobrevivência $(\%)$ & $14,1^{\mathrm{c}}$ & $32,5^{\mathrm{b}}$ & $63,3^{\mathrm{a}}$ \\
\hline
\end{tabular}

Letras distintas na mesma linha indicam diferença significativa pelo teste de Tukey $(P \leq 0,05)$.

" taxa de crescimento específico. 


\section{REFERÊNCIAS}

ANDREWS, J.W. et al. Temperature requirements for high density rearing of channel catfish from fingerling to market size. Progressive Fish Culturist, v.34, p.240-241, 1972.

ANDREWS, J.W.; STICKNEY, R.R. Interactions of feeding rates and environmental temperature on growth, food conversion, and body composition of channel catfish. Transactions of the American Fisheries Society, v.101, p.94-99, 1972.

CARDOZO, L.B. Estudo da biometria, composição corporal e composição da carcaça do Jundiá (Rhamdia sp). 2000. 65f. Dissertação (Mestrado em Zootecnia) Curso de Pós-graduação em Zootecnia da Universidade Federal de Pelotas.

CHIPPARI-GOMES, A.R. et al. Lethal temperature for Rhamdia quelen fingerlings. Journal of Applied Aquaculture, v.9, n.4, p.11-21, 1999.

CHO, S.H.; LOVELL, R.T. Variable feed allowance with constant protein input for channel catfish (Ictalurus punctatus) cultured in ponds. Aquaculture, v.204, p.101$112,2002$.

GOMES, L.C. et al. Biologia do jundiá Rhamdia quelen (TElEOSTEI, PIMELODIDAE). Ciência Rural, v.30, n.1, p.179-185, 2000.

GOMES, S.Z.; SCHLINDWEIN, A.P. Efeitos de períodos de cultivo e densidades de estocagem sobre o desempenho do Catfish (Ictalurus punctatus) nas condições climáticas do litoral de Santa Catarina. Revista Brasileira de Zootecnia, v.29, n.5, p.12661272, 2000 .

GUEDES, D.S. Contribuição ao estudo da sistemática e alimentação de jundiás (Rhamdia sp) na região central do Rio Grande do Sul (Pisces, Pimelodidae). 1980. $100 f$. Dissertação (Mestrado em Zootecnia) - Curso de Pós-graduação em Zootecnia da Universidade Federal de Santa Maria.

KIM, M.K.; LOVELL, R.T. Effect of restricted feeding regimens on compensatory weight gain and body tissue changes in channel catfish (Ictalurus punctatus) in ponds. Aquaculture, v.135, p.285-293, 1995.

LEE, J.S. Commercial catfish farming. Danville, Illinois: Interstate, 1991. 330p.

LEWIS, G.W. Channel catfish production in ponds. Athens. Extension Service. University of Georgia-College of Agriculture, 1985. 14p. (Technical Bulletin, 103).
LUCHINI, L. Manual para el cultivo del bagre sudamericano (Rhamdia sapo). Buenos Aires : INIDEP, 1992. 63p.

LOPES, J.M. et al. Survival and growth of silver catfish larvae exposed to different water pH. Aquaculture International, v.9, p.73-80, 2001.

LOVELL, T. Nutrition and feeding of fish. New York : Van Nostrand Reinhold, 1989. 260p.

MASSER, M. et al. Channel catfish production in ponds. Alabama : Cooperative Extension Service, Auburn University, 1989. 21p. (Technical Bulletin, 195).

PIEDRAS, S.R.N. Manual prático para o cultivo do channel catfish. Pelotas : EDUCAT - UCPEL, 1990. 72p.

PIEDRAS, S.R.N. et al. Viabilidade do cultivo intensivo do channel catfish (Ictalurus punctatus) na zona sul do RS. In: ENCONTRO RIO-GRANDENSE DE TÉCNICOS EM AQUICULTURA, 1991, Rio Grande. Anais... Rio Grande : FURG, 1991. p.73-77.

SATO, G.; AMARAL JUNIOR, H. Comparative growth test between gray and pink jundiá Rhamdia sp and nile tilapia Oreochromis niloticus. In: WORLD AQUACULTURE, 2003, Salvador, BA. Anais... Salvador : World Aquaculture Society, 2003. V.2, 902p. p.701.

SILFVERGRIP, A.M.C. A systematic revision of the neotropical catfish genus Rhamdia. 1996. 156f. Thesis (PhD in Zoology) - Course of Zoology, Stockholm University.

STEFFENS, W. Principios fundamentales de la alimentación de los peces. Zaragoza, Espanha : Acribia, 1987. 275p.

VARGAS, L.; MOREIRA, H.L.M. Patologia de peixes e genética e melhoramento de peixes. Maringá : FADEC UEM, 1998. 58p.

WELlborn, T.L. Channel Catfish: life history and biology. Nova Orleans : Southern Regional Aquaculture Center (SRAC), Texas Agricultural Extension Service, University of Florida. Capturado em 13 de Dezembro 1999. (Publication n.180). Online. Disponível na Internet: http:// www.farminfo.org/aquaculture/chancat.htm

ZAIONS, M.I.; BALDISSEROTTO, B. $\mathrm{Na}^{+}$and $\mathrm{K}^{+}$body levels and survival of fingerlings of Rhamdia quelen (Siluriformes, Pimelodidae) exposed to acute changes of water $\mathrm{pH}$. Ciência Rural, v.30, n.6, p.1041-1045, 2000. 